\title{
Article \\ Electrical and Mechanical Properties of Sugarcane Bagasse Pyrolyzed Biochar Reinforced Polyvinyl Alcohol Biocomposite Films
}

\author{
Kawsar Ahmed ${ }^{1,2}$, Mahbub Hasan ${ }^{1}$ and Julfikar Haider ${ }^{3, *(D)}$ \\ 1 Department of Materials and Metallurgical Engineering, Bangladesh University of Engineering and \\ Technology, Dhaka 1000, Bangladesh; kawsar7509@gmail.com (K.A.); mahbubh@mme.buet.ac.bd (M.H.) \\ 2 Hydrogen Energy Laboratory, Bangladesh Council of Scientific and Industrial Research, Chattogram 4220, \\ Bangladesh \\ 3 Advanced Materials and Surface Engineering (AMSE) Research Centre, Manchester Metropolitan University, \\ Manchester M1 5GD, UK \\ * Correspondence: j.haider@mmu.ac.uk; Tel.: +44-1612473804
}

Citation: Ahmed, K.; Hasan, M.; Haider, J. Electrical and Mechanical Properties of Sugarcane Bagasse Pyrolyzed Biochar Reinforced Polyvinyl Alcohol Biocomposite Films. J. Compos. Sci. 2021, 5, 249. https://doi.org/10.3390/jcs5090249

Academic Editor:

Francesco Tornabene

Received: 8 August 2021

Accepted: 14 September 2021

Published: 18 September 2021

Publisher's Note: MDPI stays neutral with regard to jurisdictional claims in published maps and institutional affiliations.

Copyright: (c) 2021 by the authors. Licensee MDPI, Basel, Switzerland. This article is an open access article distributed under the terms and conditions of the Creative Commons Attribution (CC BY) license (https:// creativecommons.org/licenses/by/ $4.0 /)$.
Abstract: Biochar obtained from the oxygen-deficient thermochemical processing of organic wastes is considered to be an effective reinforcing agent in biocomposite development. In the present research, biocomposite film was prepared using sugarcane bagasse pyrolyzed biochar and polyvinyl alcohol (PVA), and its electrical and mechanical properties were assessed. The biocomposite films were produced by varying content ( $5 \mathrm{wt} . \%, 8 \mathrm{wt} . \%$ and $12 \mathrm{wt} . \%$ ) of the biochar produced at $400{ }^{\circ} \mathrm{C}$, $600{ }^{\circ} \mathrm{C}, 800{ }^{\circ} \mathrm{C}$ and $1000{ }^{\circ} \mathrm{C}$ and characterized using X-Ray diffraction, scanning electron microscope, Fourier transform infrared spectroscopy. The experimental findings revealed that biochar produced at a higher pyrolyzing temperature could significantly improve the electrical conductance of the biocomposite film. A maximum electrical conductance of $7.67 \times 10^{-2} \mathrm{~S}$ was observed for $12 \mathrm{wt}$. $\%$ addition of biochar produced at $1000{ }^{\circ} \mathrm{C}$. A trend of improvement in the electrical properties of the biocomposite films suggested a threshold wt.\% of the biochar needed to make a continuous conductive network across the biocomposite film. Rapid degradation of tensile strength was observed with an increasing level of biochar dosage. The lowest tensile strength $3.12 \mathrm{MPa}$ was recorded for the film with $12 \mathrm{wt} . \%$ of biochar produced at $800{ }^{\circ} \mathrm{C}$. Pyrolyzing temperature showed a minor impact on the mechanical strength of the biocomposite. The prepared biocomposites could be used as an electrically conductive layer in electronic devices.

Keywords: sugarcane bagasse; pyrolysis; biochar; PVA; biocomposite film; electrical conductance

\section{Introduction}

Judicious dumping of biomass or organic waste is necessary to avoid undesired climate change that causes large scale natural imbalance [1,2]. Organic waste generates environmentally harmful greenhouse gases (GHG) [3]. The use of synthetic products or petrochemicals in thermochemical treatment is just adding harmful gases in the air every day [4]. The conversion of organic waste into value-added products through thermochemical treatment like pyrolysis can be regarded as an effective way of mitigating pollution caused by these wastes with an opportunity to save and conserve energy [5]. Pyrolyzing conditions, e.g., temperature, heating rate, media, etc., are the controlling parameters that influence the ultimate properties of biochar. A slower heating rate and longer duration of thermal treatment were suggested to obtain biochar with turbostratically stacked graphene sheet [6]. Being a renewable and sustainable material, and with low production cost, biochar shows promise as a reinforcing material as well in agricultural applications [2]. Tunable properties, such as porosity and surface functionality, of the biochar make it a potential candidate for designing materials in energy storage, catalysis, pollutant removal, and $\mathrm{CO}_{2}$ capture applications. Besides, the high thermal stability 
and porous honeycomb structure of the biochar favor the fabrication of composites with improved properties [7].

The need for reinforced composite materials has increased noticeably, and so the biochar-based composites as well. Graphene, carbon nanotubes (CNT), carbon fiber, and carbon black are mostly used as the carbonaceous reinforcing and conductive fillers in polymer composites development [7,8]. Petrochemical-based carbonaceous materials production is a tedious job, and it is not economically and environmentally viable. Globally, research on the exploration of renewable carbon resources is ongoing to obtain feedstock is cost-effective, environmentally friendly, and is abundant in nature. Recently, numerous studies on the successful incorporation of biochar in different polymer matrixes have been reported [9-11]. Biochar is considered preferentially because of having a large surface area, porous structure, and high content of carbon that facilitates physical bonding with the polymer matrix [7]. Biochar is more advantageous than the natural fibers as the filler in polymer composites since the properties of biochar can be altered by modifying the pyrolysis conditions for achieving the hydrophobic nature in biochar and to obtain greater compatibility with the polymer matrix than the hydrophilic natural fibers [7]. In general, carbonaceous fillers are better than the metal fillers in modifying the thermal, mechanical, electrical, and finally chemical corrosion resistance properties of the polymer [10,12]. Incorporating these properties would make the designed composites applicable for the electronics industry [7]. Giorcelli et al. successfully used high temperature annealed electrically conductive biochar to develop energy conservative piezoresistive composite materials [13]. Some distinctive features of the fillers and matrix determine the end properties of the composites. For instance, filler dispersion and formation of a continuous conductive network with a threshold amount of the filler determine electrical conductivity of the final composites [14].

A biocomposite is a material composed of two or more distinct constituent materials (one being naturally derived) which are combined to yield a new material with improved performance over individual constituent materials. A frequently studied biocomposite is natural-fiber-reinforced biopolymer composite. The reinforcing component is natural fiber or cellulose extracts combined with a bioplastic matrix. The application of biochar in fabricating biocomposites could promote the sustainable management of environmental waste. Recently, biochar has been used extensively due to its distinct properties mentioned earlier [15]. A large number of studies on biochar based biocomposite were conducted using various polymers with manifold thermal, mechanical, and electrical properties in some prominent works. For example, Poly (lactic acid), Poly (ethylene-alt-maleic anhydride) with microwave assisted biochar by Khui [16], polylactic acid with biochar nanoparticle by Sobhan et al. [17], polylactic acid with activated biochar by Sobhan et al. [18], epoxy with Bael shells and arhar stalk biochar by Minugu et al. [19], polyvinyl alcohol with corn straw derived biochar along with silver nano particle by Zhao et al. [20], polyesters with rice husk pyrolyzed biochar by Richard et al. [9], polyamides with biochar by Huber et al. [21], styrene-butadiene rubber (SBR) with maple wood waste derived biochar by Peterson and Kim [22], poly (vinyl alcohol) with wood biochar (PVA) by Nan et al. [6], epoxy with three types of biochar (plastic waste biochar, wood shavings biochar, and pine cone char) by Ahmetli et al. [23], poly (trimethylene terephthalate) (PTT) with lignin carbonized biochar by Myllytie et al. [24], polypropylene with pine wood biochar by Das et al. [10,11], poly (trimethylene terephthalate/poly (lactic acid) (PTT/PLA) blend with Miscanthusbased biochar by Nagarajan et al. [25], polyurethane with carbon nanotube and graphite oxide particles by Gaidukovs et al. [26], and ethylene vinyl acetate copolymer composite filled with carbon nanotubes to investigate electrical and mechanical characteristics by Gaidukovs et al. [27]. Povilas et al. [28] investigated thermal and dielectric properties of the composites prepared with carbon and $\mathrm{Fe}_{3} \mathrm{O}_{4}$ nanoparticles and layered ethylene vinyl acetate. Minugu et al. used three different loading levels (2 wt.\%, 4 wt. \%, and 6 wt.\%) of biochar and maximum tensile strength found for the composite with $4 \mathrm{wt}$.\% biochar [19]. A further increase of biochar to $6 \mathrm{wt}$.\% decreased the strength because of poor interfacial bonding between the polymer matrix and biochar. Nan et al. reported that a composite of 
polyvinyl alcohol (PVA) with wood-based biochar of $2 \mathrm{wt} . \%$ and $10 \mathrm{wt} . \%$ exhibited electrical properties similar to those of PVA with graphene and carbon nanotubes [6]. They also found that the tensile strength decreased with the rise of the biochar loading level and a threshold amount of biochar was required to obtain an electrically conductive biocomposite.

Being a low cost, non-toxic, and water-soluble polymer, polyvinyl alcohol or PVA is commonly used for carbon-based composite fabrication. Having a hydroxyl group, it can form a strong interfacial bond with numerous reinforcing materials. PVA based carbonaceous composites have superior electrical and comparable thermal properties. However, these composites have some drawbacks, e.g., filler stacking or high preparation cost and complexity in processing [29]. High moisture sensitivity of PVA based composites is a major challenge as this influences the electrical properties. Some chemical changes or use of certain coating materials to reduce the moisture uptake are suggested to overcome the issue [30].

A large quantity of sugarcane bagasse (SB) is produced in Bangladesh every year. Bagasse is mostly used as fuel, and unfortunately, most is left untreated as waste, creating environmental issues. A small amount is used for animal feed and domestic fuel. Utilization of this huge amount of biowaste can be a solution to waste management by converting them into emerging raw material for many purposes [31]. Sugarcane bagasse contains a significant amount of cellulose and lignin that are mainly responsible for producing good quality biochar through pyrolysis [32].

According to the authors' best knowledge, no study so far has reported investigating the properties of polyvinyl alcohol biocomposites reinforced with SB pyrolyzed biochar. In the present research, sugarcane bagasse pyrolyzed biochar reinforced PVA biocomposite films were produced and characterized. Biochar was characterized by proximate analysis, X-ray diffraction (XRD), and Fourier transform infrared spectroscopy (FTIR) and scanning electron microscopy (SEM), and the biocomposite films were characterized by, SEM, FTIR, impedance analysis (IA), and tensile testing.

\section{Materials and Methods}

\subsection{Preparation and Characterization of SB Pyrolyzed Biochar}

Clean and dry sugarcane bagasse collected from the local area was pyrolyzed without delignifying the bagasse in a stainless-steel container by electric muffle furnace at four different temperatures $\left(400,600,800\right.$, and $\left.1000^{\circ} \mathrm{C}\right)$ with a heating rate of $10^{\circ} \mathrm{C} / \mathrm{min}$ for one hour to produce good quality biochar (Figure 1). After cooling down to room temperature, biochar was ground to powder form, sieved, and then kept in closed containers, labeled as BC400, BC600, BC800, and BC1000, where BC stands for biochar and numbers indicate the pyrolyzing temperatures. The biochar produced at different temperatures was used for preparing the biocomposite film. No compositional (cellulose, hemicellulose, sugar etc.) characterization was conducted for the biochar. Syn-gas and bio-oil were not stored as those were not the focus of the present research.

Proximate analysis of the prepared biochar was carried out following ASTM standard D1762-84. The crystallographic structure was revealed through X-ray diffraction (XRD) ( $2 \theta=20^{\circ}$ to $80^{\circ}$ and scanning rate $0.5^{\circ} / \mathrm{min}$ ), Model-EMMA, GBC Corporation, Australia. Surface morphology and functional groups are investigated through the SEM (Model: EVO18 with gold coat facilities at an acquisition voltage of $20 \mathrm{kV}$ ).

\subsection{Preparation and Characterization of Biocomposite Films}

Polyvinyl alcohol (PVA)from Merk, Germany was used in the present research and collected from the local market. Its molecular weight and density were 145,000 and $1.19 \mathrm{~g} / \mathrm{cm}^{3}$ respectively. A clear and viscous solution of $10 \mathrm{wt} . \%$ PVA was prepared by stirring distilled water and PVA mixture at $80{ }^{\circ} \mathrm{C}$ for four hours. A schematic diagram covering the preparation of the biocomposite films and their characterization techniques is presented in Figure 2. 


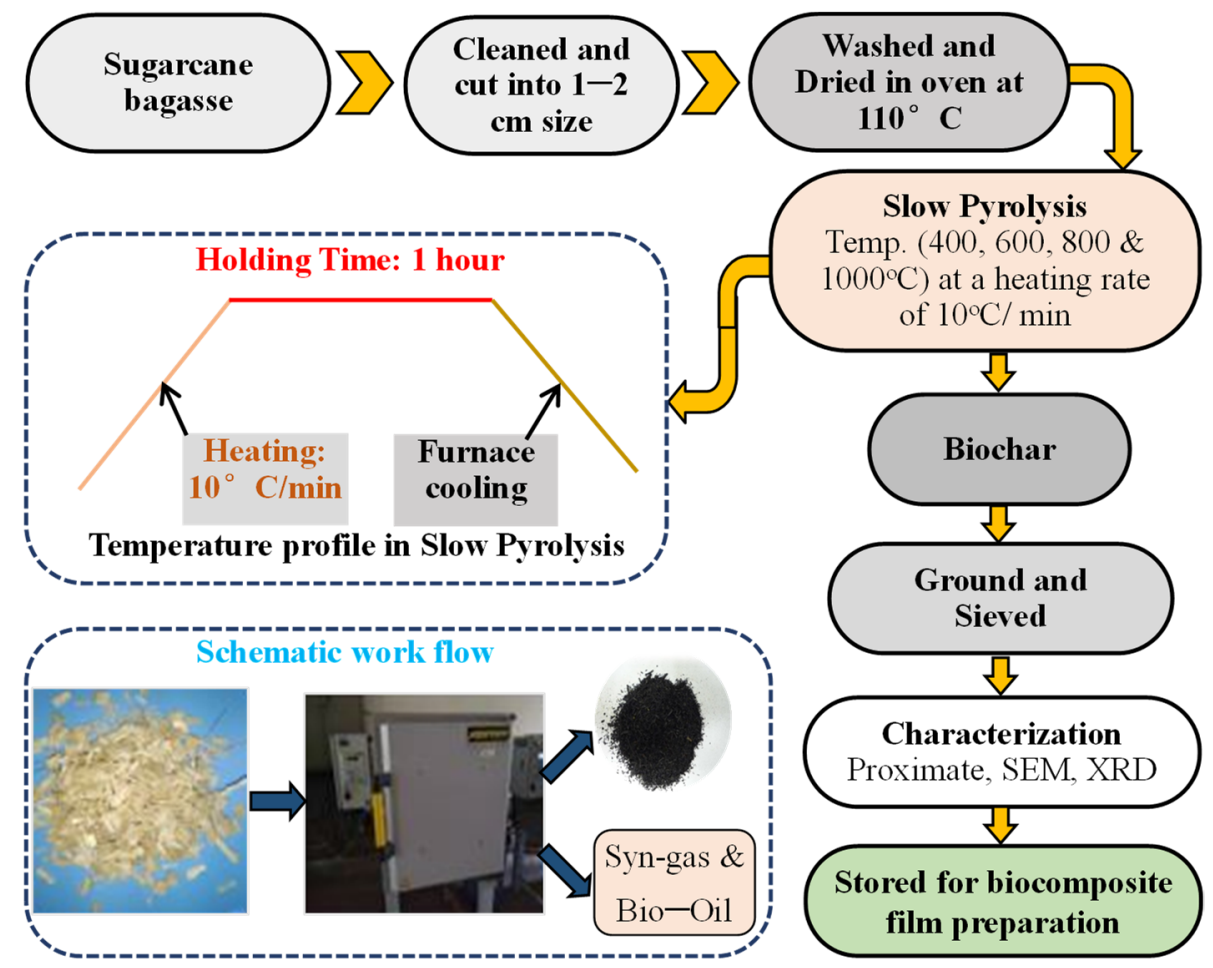

Figure 1. Sugarcane bagasse pyrolyzed biochar preparation.

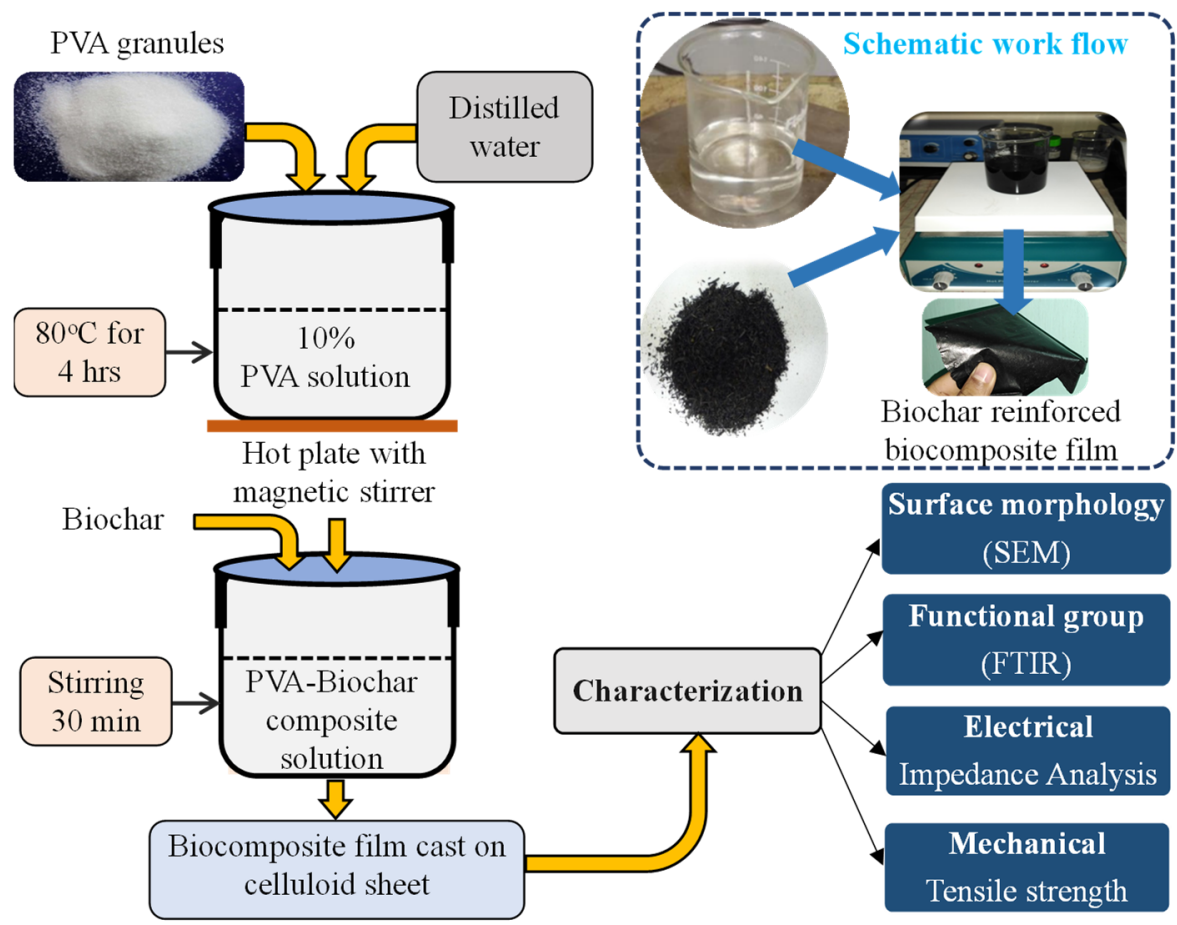

Figure 2. Preparation of biocomposite films with sugarcane bagasse pyrolyzed biochar.

Two types of sample were prepared by varying the temperature and biochar loading level. Biocomposite films with $5 \mathrm{wt}$.\% biochar produced at four different pyrolyzing temperatures (BC400, $\mathrm{BC} 600, \mathrm{BC} 800$, and $\mathrm{BC} 1000)$ were prepared to observe the influence of pyrolyzing temperature. As the possibility of graphite formation starts after $800{ }^{\circ} \mathrm{C}$, only two types of biochar (BC800, and BC1000) were selected with higher level of dosage ( $8 \mathrm{wt} . \%$ and $12 \mathrm{wt} . \%)$. For each sample film, biochar was added with $20 \mathrm{~mL}$ PVA solution and 
stirred for $30 \mathrm{~min}$ at room temperature. This solution was allowed to set, and films were cast on celluloid sheets. Dried biocomposite films with a thickness of $0.25 \mathrm{~mm}$ were peeled out after $24 \mathrm{~h}$ and stored in an airtight container for characterization. The biocomposite films are designated as shown in Table 1.

Table 1. Biocomposite film samples with identification code and biochar content.

\begin{tabular}{ccc}
\hline Biocomposite Film ID & \multicolumn{3}{c}{ Biochar Content (wt.\%) } \\
\hline Pure PVA & 5 & No biochar \\
5BC400-PVA & 5 & BC400 \\
5BC600-PVA & 5 & BC600 \\
\hline 5BC800-PVA & 8 & BC800 \\
8BC800-PVA & 12 & \\
12BC800-PVA & 5 & BC1000 \\
5BC1000-PVA & 8 & \\
8BC1000-PVA & 12 & \\
12BC1000-PVA & &
\end{tabular}

The surface morphology and functional group of pure PVA and biocomposite films were studied with SEM and FTIR respectively. The electrical property (Conductance, Siemens) of biocomposite films was tested with an impedance analyzer (model: 6500B), at $100 \mathrm{~Hz}$ at room temperature. The tensile property of the biocomposite films were characterized using an Instron 3380 Series Universal Testing Machine (UTM) having a capacity of $50 \mathrm{kN}$. The dogbone shape sample dimension was $40 \mathrm{~mm}$ (length) $\times 10 \mathrm{~mm}$ (width) $\times$ $0.25 \mathrm{~mm}$ (thickness) with $6.25 \mathrm{~mm}$ width at the gauge length zone. The cross-head speed used during the test was $5 \mathrm{~mm} / \mathrm{min}$. Tests were repeated five times to obtain an average value of each composite.

\section{Results and Discussions}

\subsection{Biochar Analysis}

\subsubsection{SEM Analysis of Biochar}

Scanning electron microscope (SEM) images of surface morphology of four types of biochar in unsieved condition are shown in Figure 3. As the biochar was ground properly, the particle size of the biochar was reduced to 2-10 $\mu \mathrm{m}$. The biochar particle size of approximately $15 \mu \mathrm{m}$ was observed in some cases. The small size of the porous structure $(15-20 \mu \mathrm{m})$ in biochar at higher temperatures was also revealed from the SEM analysis. A flake-like appearance was visible in both BC400 and BC600 biochar having no porous structure. Biochar (BC800) produced at $800^{\circ} \mathrm{C}$ exhibited a more visible porous structure followed by the BC1000. All the biochar contained randomly distributed brittle particles and no agglomeration or compressed form of biochar was seen. Small particle size and porous structure increased the surface area of the biochar particles and made it a suitable choice for composite development. The biochar exhibited less interaction between the particles and tends to appear as an individual particle with broad particle size distribution. The individual and broad particle size distribution of the biochar would facilitate good dispersion in the PVA matrix. As reported by Ahmetli et al. [23], biochar particles distributed well in the matrix and provided good interaction between the char and the polymer matrix. No crack was found on the particle of biochar. Porous structure within the biochar will not only increase the penetration of polymer matrix into the biochar, but will also enhance the interlocking between the PVA matrix and the biochar, thus enhancing the mechanical strength of the biocomposite. 


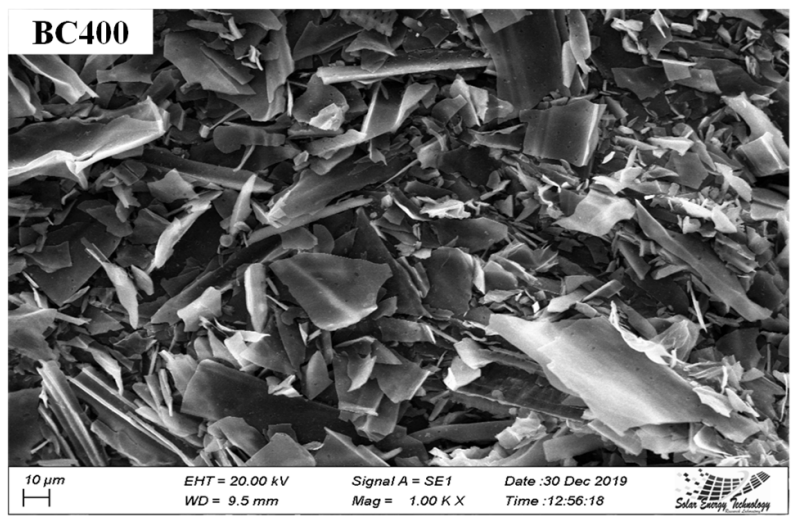

(a)

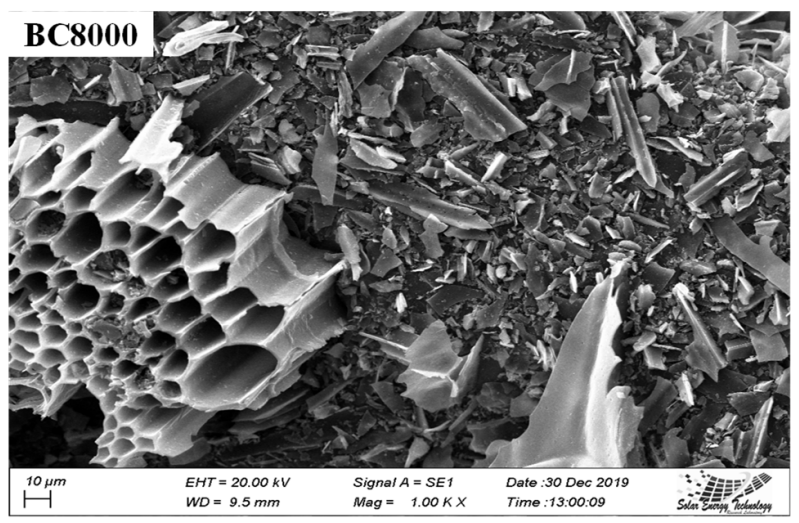

(c)

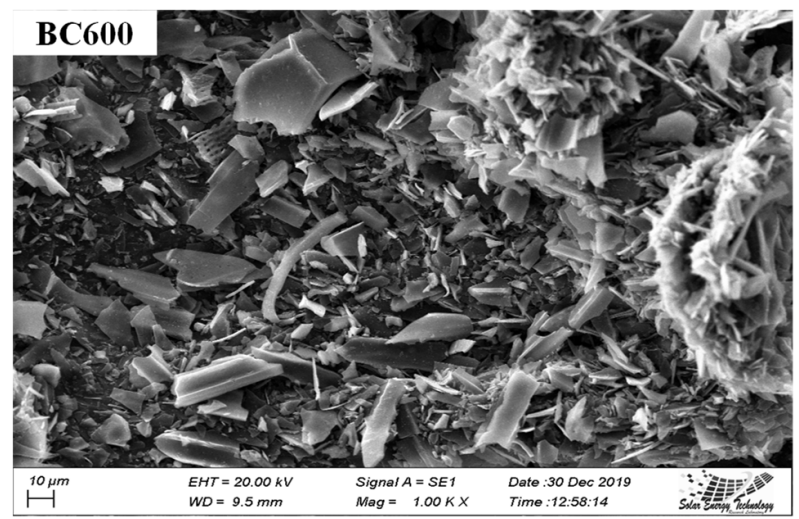

(b)

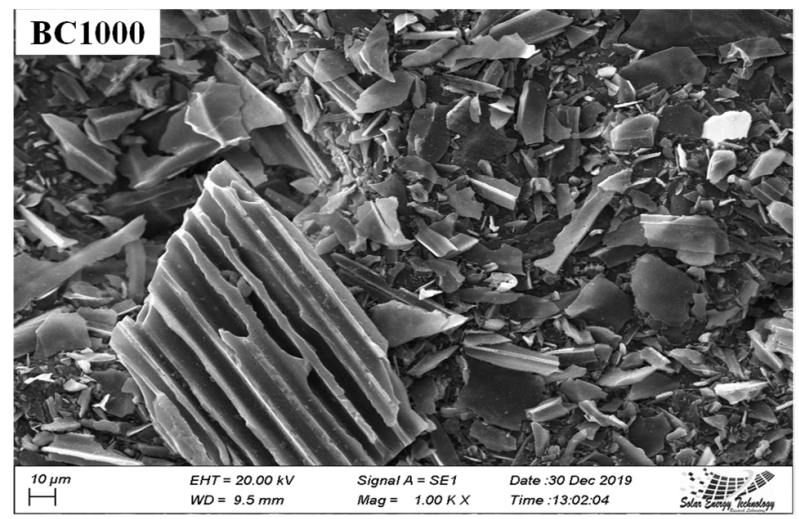

(d)

Figure 3. SEM images of biochar produced at different pyrolyzing temperatures (a) $400{ }^{\circ} \mathrm{C}\left(\right.$ b) $600{ }^{\circ} \mathrm{C}$ (c) $800{ }^{\circ} \mathrm{C}$ and (d) $1000^{\circ} \mathrm{C}$.

\subsubsection{Proximate Analysis of Biochar}

Table 2 represents proximate analysis of the biochar at different pyrolyzing temperatures. There is a noticeable reduction in biochar yield from $30.10 \mathrm{wt}$ \% to $14.67 \mathrm{wt} \%$ with a rise in pyrolyzing temperature from $400{ }^{\circ} \mathrm{C}$ to $1000{ }^{\circ} \mathrm{C}$. A similar trend reported by Xie et al. [5] also indicated that a high content of hydrogen and oxygen in biochar was obtained at lower pyrolyzing temperatures. However, an increase in moisture content from $3.69 \%$ to $8.96 \%$, ash content from $4.05 \%$ to $6.57 \%$, and fixed carbon from $52.23 \%$ to $70.82 \%$ were recorded with the temperature rise from $400{ }^{\circ} \mathrm{C}$ to $1000{ }^{\circ} \mathrm{C}$. On the other hand, volatile materials decreased significantly due to the temperature rise in a similar manner. These results agreed with the previous findings in literature [32-35]. Therefore, the biochar obtained at pyrolyzing temperature of $1000{ }^{\circ} \mathrm{C}$, when intense graphitization occurs, can be a better choice for electronic device applications.

Table 2. Proximate analysis of biochar at different pyrolyzing temperatures.

\begin{tabular}{ccccc}
\hline \multirow{2}{*}{ Measured Parameters (wt.\%) } & \multicolumn{4}{c}{ Pyrolyzing Temperature $\left({ }^{\circ} \mathbf{C}\right)$} \\
\cline { 2 - 5 } & $\mathbf{4 0 0}$ & $\mathbf{6 0 0}$ & $\mathbf{8 0 0}$ & $\mathbf{1 0 0 0}$ \\
\hline Moisture & 3.69 & 5.38 & 12.33 & 16.96 \\
Volatile materials & 40.03 & 22.44 & 16.19 & 13.65 \\
Ash content & 4.05 & 5.15 & 6.33 & 6.57 \\
Fixed carbon $^{a}$ & 52.23 & 67.03 & 65.15 & 62.82 \\
Biochar yield $^{a}$ & 30.10 & 20.15 & 17.51 & 14.67 \\
\hline
\end{tabular}

${ }^{a}$ calculated by deduction. 


\subsubsection{XRD Analysis of Biochar}

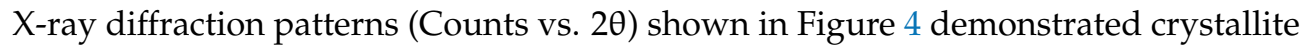
features of the biochar. Peaks at $\sim 24^{\circ} \mathrm{C}$ and $\sim 44.5^{\circ} \mathrm{C}$ were characterized in the biochar produced at different temperatures. The strong peak at $\sim 44.5^{\circ} \mathrm{C}$ indicated the formation of a graphite-like structure in biochar at high temperatures (BC800 and BC1000) such as, $800{ }^{\circ} \mathrm{C}$ and $1000{ }^{\circ} \mathrm{C}$ (Figure 4c,d). However, for the biochar BC400 and BC600, the XRD line went straight down without featuring any significant peak at around $24^{\circ} \mathrm{C}$. However, for the $\mathrm{BC} 800$ and $\mathrm{BC} 1000$, the XRD pattern revealed a small peak at around $24{ }^{\circ} \mathrm{C}$ and it was more intense for the $\mathrm{BC} 1000$. This finding indicated that $2 \theta$ peaks for graphite crystal appeared at around $24{ }^{\circ} \mathrm{C}$ for (002) plane and $44.5^{\circ} \mathrm{C}$ for (100) plane. The peak from the (100) plane represented the graphite basal plane and that from the (002) plane represented the plane perpendicular to the basal plane [36]. This graphite-like structure was turbostratically stacked, the parallel orientation of carbon chain, and responsible for the electrical conductivity of the biocomposite materials [7].

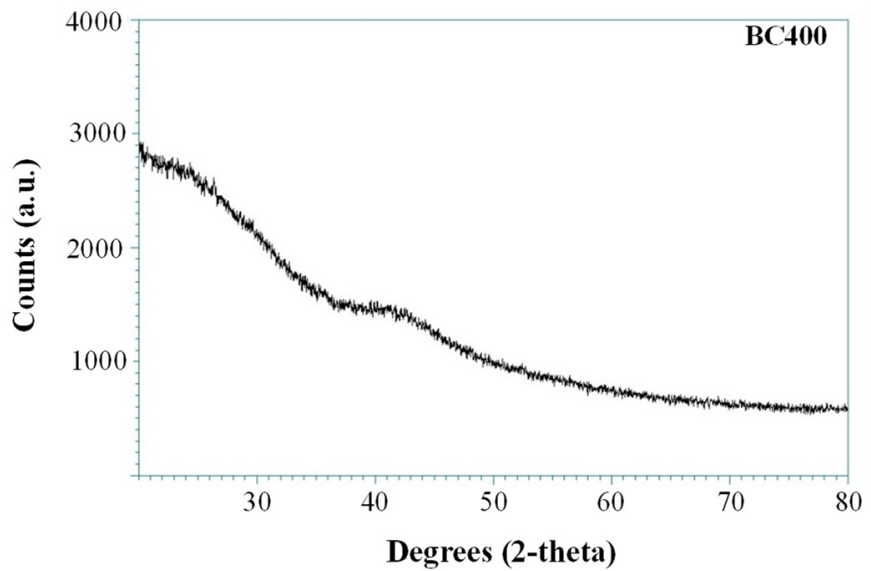

(a)

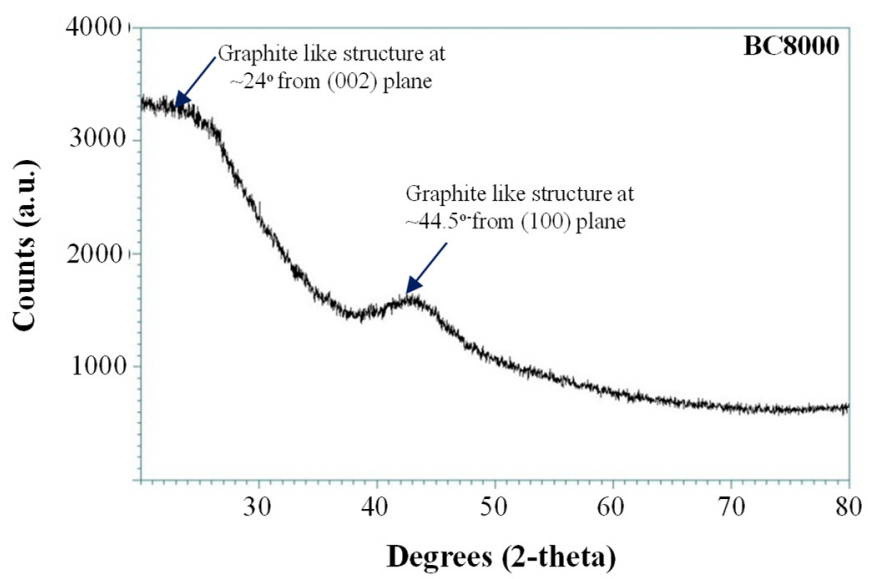

(c)

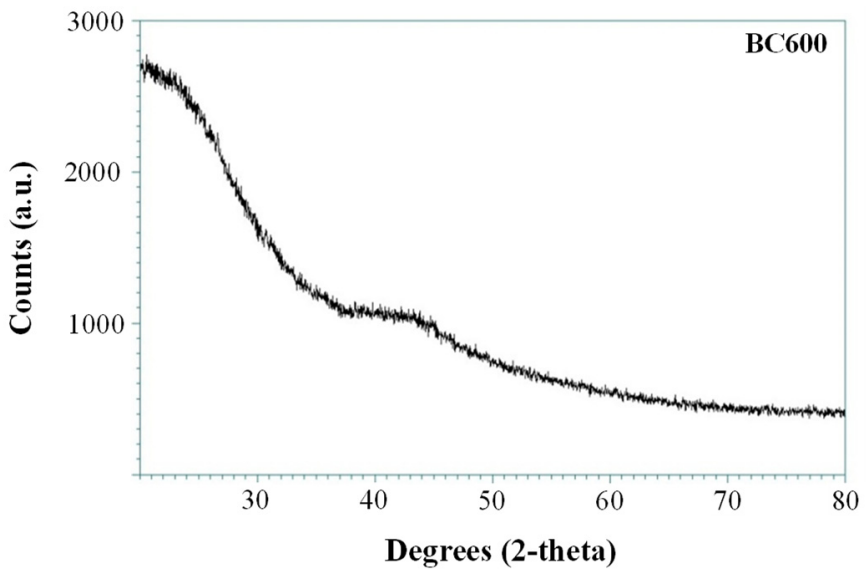

(b)

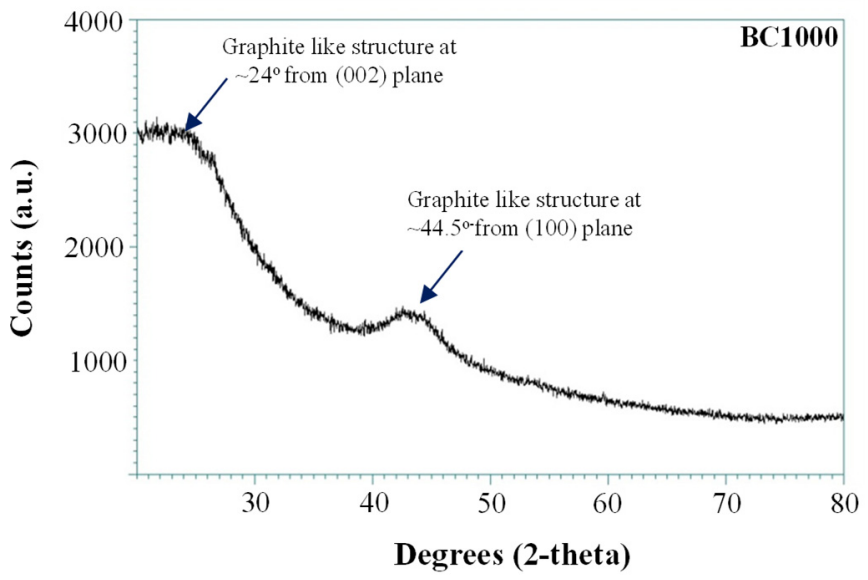

(d)

Figure 4. X-ray diffraction pattern of SB biochar produced at pyrolyzing temperatures (a) $400{ }^{\circ} \mathrm{C}\left(\right.$ b) $600{ }^{\circ} \mathrm{C}(\mathbf{c}) 800{ }^{\circ} \mathrm{C}$ and (d) $1000^{\circ} \mathrm{C}$.

\subsection{Analysis of Biocomposite Films}

\subsubsection{Surface Characteristics of the Biocomposite Films}

SEM images of the biochar reinforced biocomposite films are presented in Figure 5, where the pure PVA film was very clear, with no visible surface features. Small biochar addition (5 wt.\%) with the PVA matrix introduced surface roughness in the biocomposite film and random particle distribution or agglomeration was also observed. The emergence of severe particle agglomeration was noticed for a further gradual increase in biochar 
loading from $5 \mathrm{wt}$ \% to $8 \mathrm{wt} . \%$ and to $12 \mathrm{wt} . \%$. SEM images revealed insight of changing mechanical strength remarkably. Biochar aggregation and distribution revealed by the SEM images resulted in lower tensile strength (shown later) and higher electrical conductance. The higher the biochar content, the higher the particle aggregation and stacking, and the greater the deterioration of mechanical strength, as reported previously $[6,8,37]$.

\subsubsection{FTIR Analysis of the Biocomposite Films}

The effect of biochar addition with the PVA matrix on the functional group is illustrated in Figure 6. The identical peak around $3300 \mathrm{~cm}^{-1}$ wavenumber revealed by pure PVA film was almost invisible after the incorporation of the biochar. The effects of BC600 and BC1000 were more than that of the BC400 and BC800. The decrease in peak intensity at approximately $2930 \mathrm{~cm}^{-1}, 1400 \mathrm{~cm}^{-1}$, and $1080 \mathrm{~cm}^{-1}$ corresponding to $-\mathrm{CH}_{2}-$ asymmetric stretching, $-\mathrm{CH}_{2}$ - bending stretching, and $-\mathrm{C}-\mathrm{O}-\mathrm{H}$ stretching vibration indicated that biochar functional groups developed during pyrolysis could strongly interact with these groups. This observation indicated that the biochar could form a chemical bond with the PVA matrix during the biocomposite film formation, which indicated the good compatibility between biochar and PVA [3,30,38]. The absence of intensity of peak for -OH indicated lower moisture content in the biochar than that in the PVA and hydrogen bond formation with -OH in the PVA and the oxygen containing group in the biochar. No emergence of a new functional group was revealed from the FTIR data.
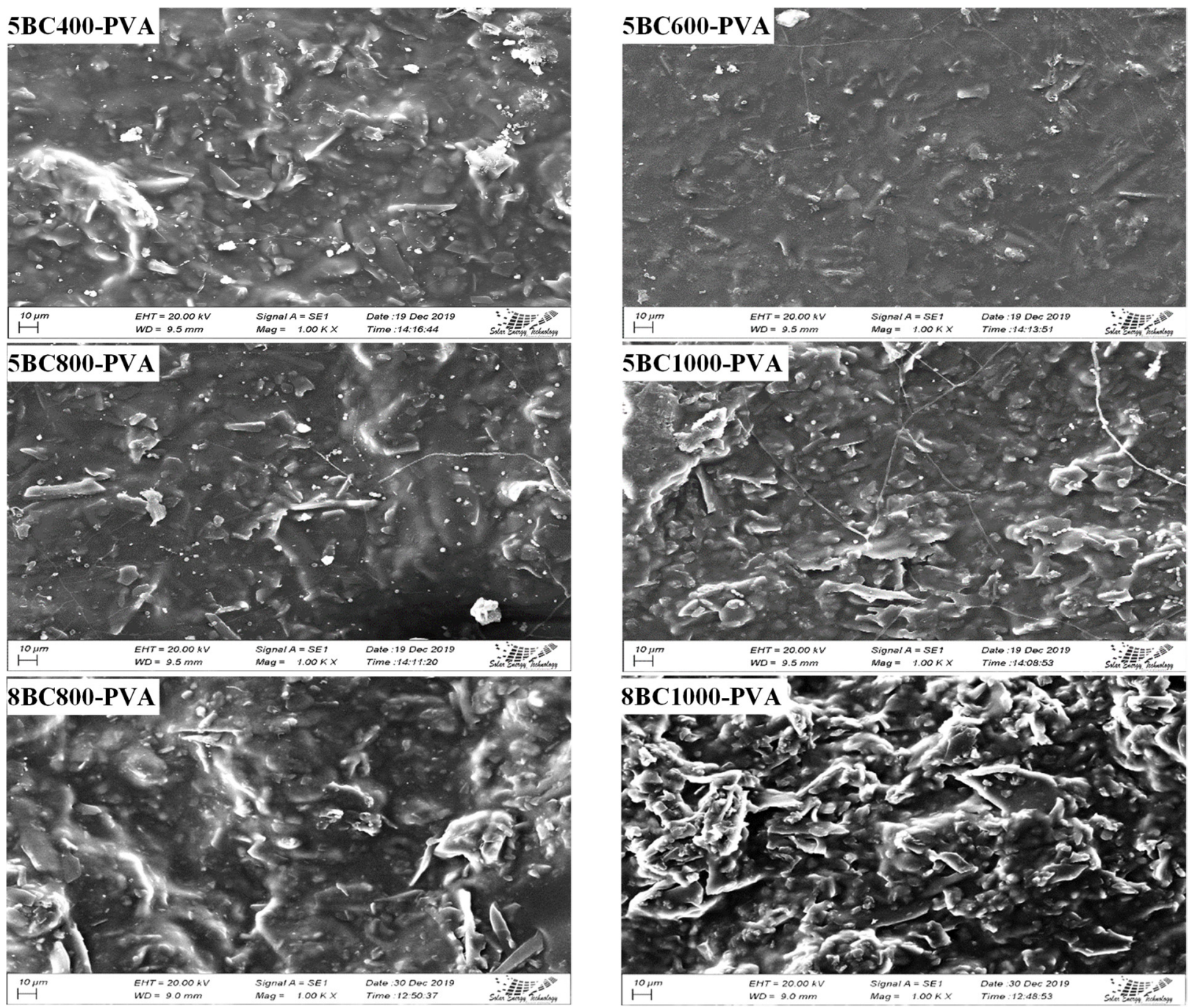

Figure 5. Cont. 

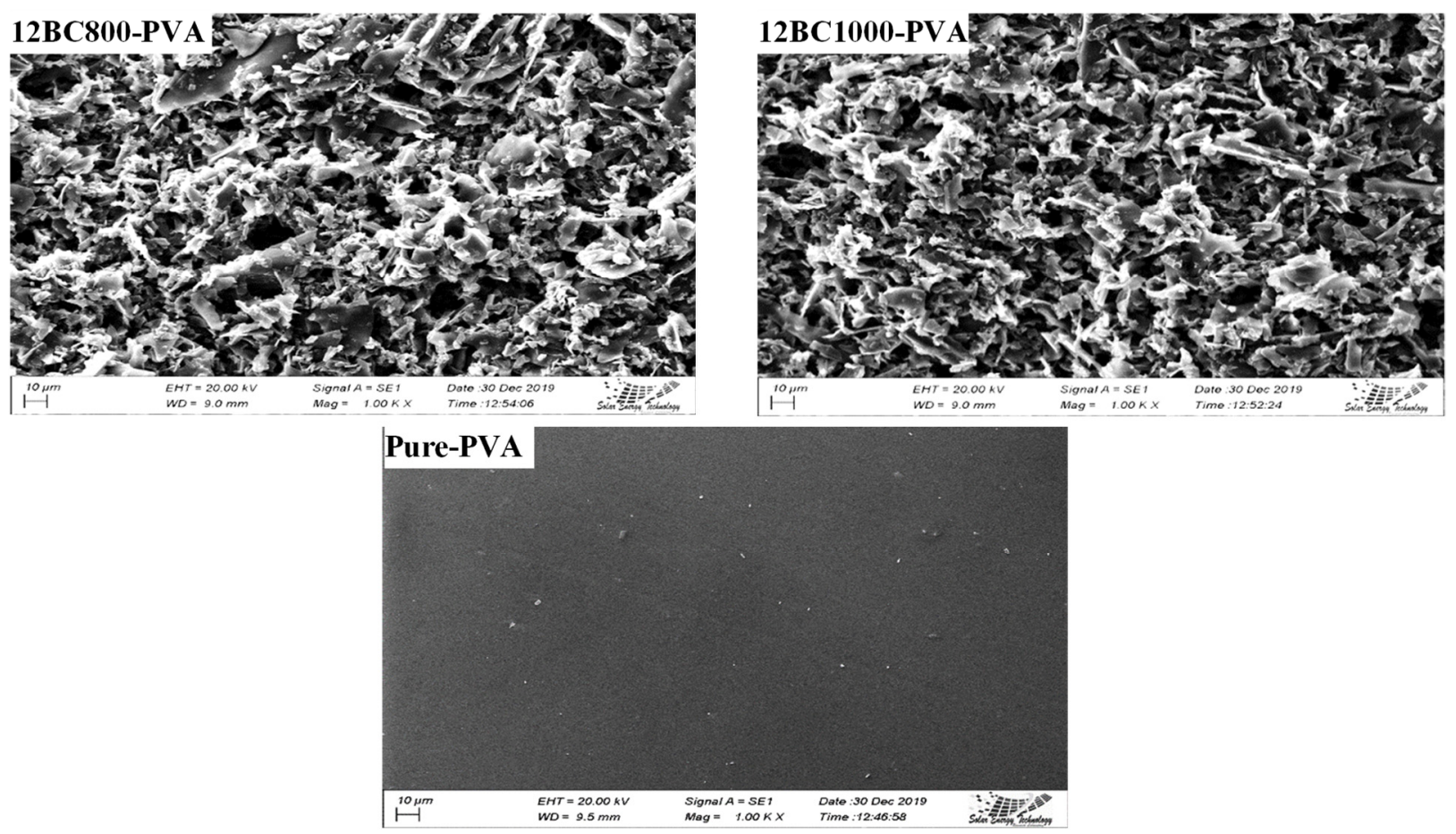

Figure 5. Surface characteristics of the biochar reinforced biocomposite films.

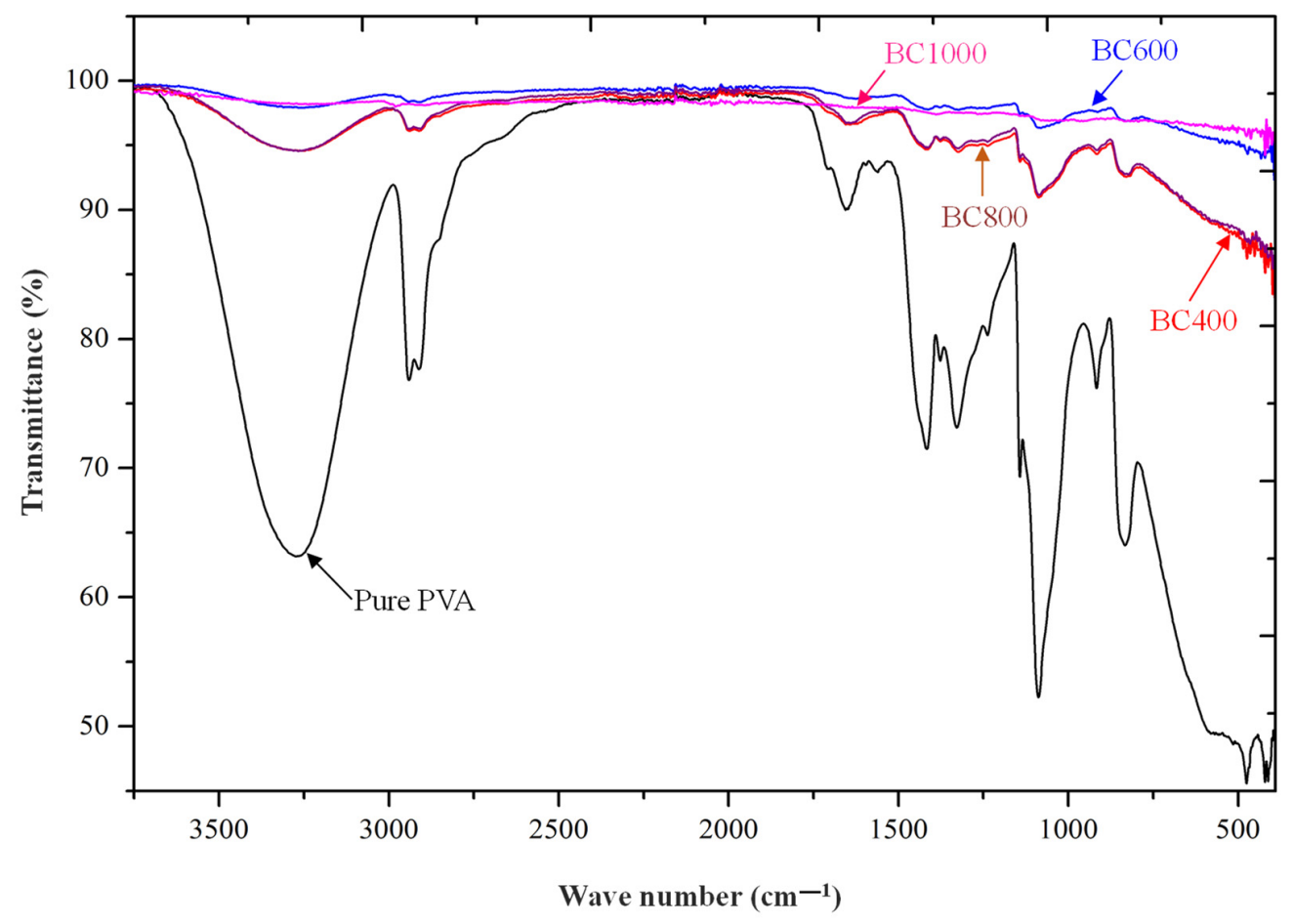

Figure 6. FTIR spectrum of biochar reinforced biocomposite films.

\subsubsection{Electrical Conductance of the Biocomposite Films}

The electrical property of the biocomposite films was studied by measuring electrical conductance (Siemens, S) using an impedance analyzer at room temperature. The results of electrical conductance measurement are shown in Figures 7 and 8. Pure PVA showed very low conductance value $\left(1.86 \times 10^{-7} \mathrm{~S}\right)$ indicating an insulator. The biocomposite films with 5 wt.\% of biochar (BC400, BC600, BC800) did not show any conductance, except the 
5BC1000-PVA film, which exhibited a significant improvement in electrical conductance to $1.91 \times 10^{-2} \mathrm{~S}$ (Figure 7). Further, $8 \mathrm{wt} . \%$ and $12 \mathrm{wt.} \%$ addition of BC800 generated conductance of $3.63 \times 10^{-8} \mathrm{~S}$ and $2.38 \times 10^{-2} \mathrm{~S}$ respectively. This implied that a threshold content of the biochar is necessary to form a conductive continuous network across the biocomposite films. With the addition of $8 \mathrm{wt} . \%$ and $12 \mathrm{wt} . \% \mathrm{BC} 1000$, the electrical conductance increased approximately three and four times respectively as compared to that of the 5BC1000-PVA film (Figure 8).

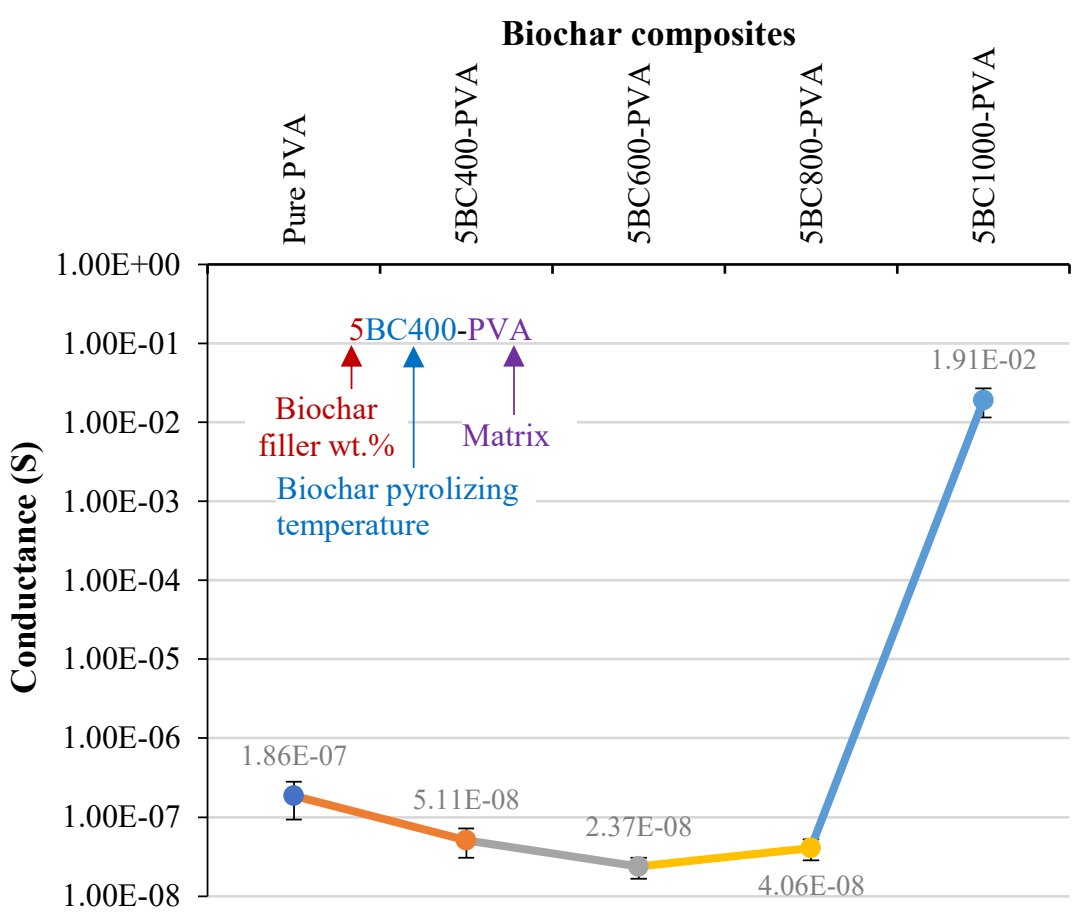

Figure 7. Effect of biochar pyrolyzed at the different temperatures on electrical properties of biocomposite films.

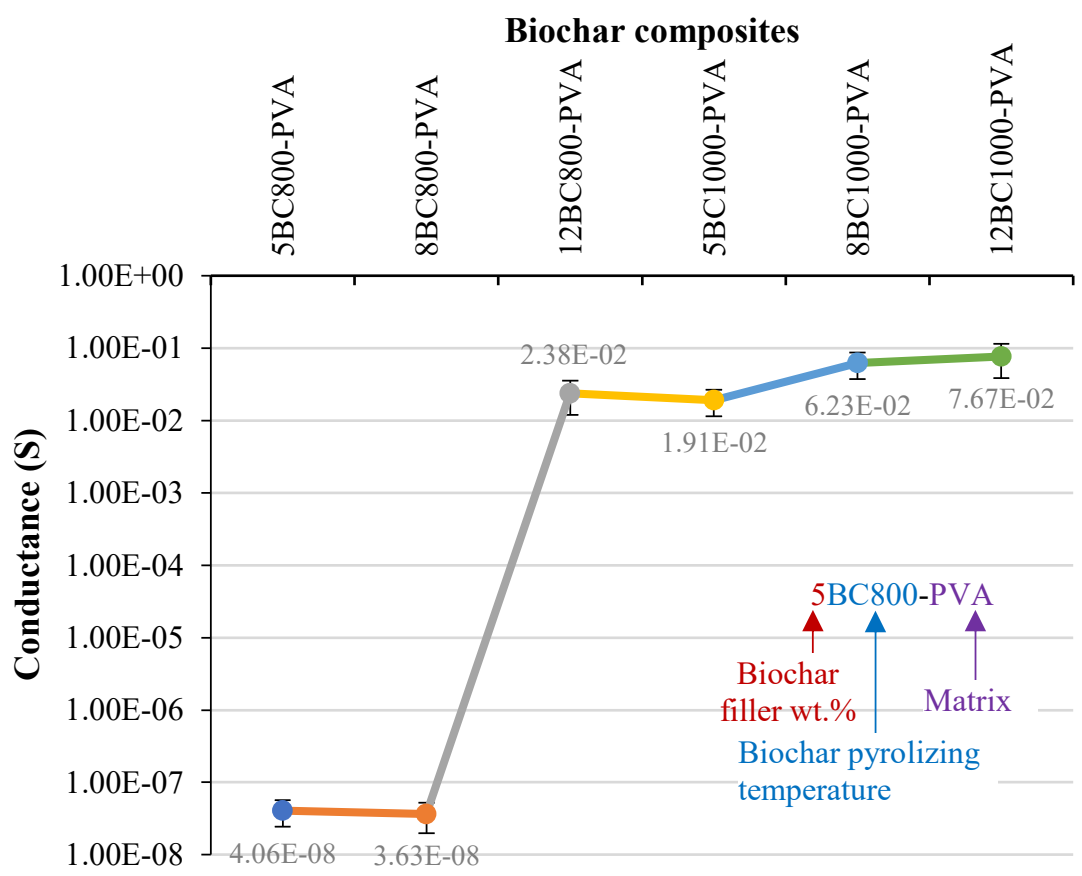

Figure 8. Effect of loading level of BC800 and BC1000 on electrical properties of biocomposite films. 
The presence of ash impurities and non-graphitic carbon that made a barrier to form a continuous conductive network could be the cause behind the lower conductance of biocomposite films, particularly at low biochar content obtained at low pyrolyzing temperature $[5,8]$. The intensity of graphite formation increased with the rise of pyrolyzing temperature [5]. The XRD pattern confirmed the formation of electrically conductive graphitic carbon that contains delocalized pi-electrons and was responsible for the conduction of biocomposite films [7,8]. The incorporation of graphitic carbon rich biochar that forms a conductive, continuous network of across the PVA film was the key reason to make the biocomposite film electrically conductive [6]. Sobhan et al. reported improved electrical conductance by increasing the biochar loading level [16]. The higher quantity of graphitic carbon-based fillers, e.g., graphene, grapheme oxide, carbon nanotube, and biochar, ensured the proper dispersion of electrically conductive graphitic carbon across the polymer matrix [39-41].

\subsubsection{Tensile Strength of Biocomposite Films}

Tensile tests were conducted to observe mechanical characteristics of the biocomposite films. The effect of pyrolyzing temperatures and biochar loading levels on tensile strength of the biocomposite films are shown in Figures 9 and 10, respectively. The biocomposites with $5 \mathrm{wt} . \%$ biochar showed lower tensile strength as compared to that of the pure PVA. The tensile strength of the biocomposite films increased gradually from $7.75 \mathrm{MPa}$ for $\mathrm{BC} 400$, to $8.33 \mathrm{MPa}$ and $8.75 \mathrm{MPa}$ for $\mathrm{BC} 600$ and $\mathrm{BC} 800$, respectively. Tensile strength then reduced again to $5.82 \mathrm{MPa}$ for $\mathrm{BC} 1000$. This implied the development of strong cross-linking and adhesion between PVA matrix and biochar, which occurred because of various functional groups, fibrous residue, and porosity present in biochar [42]. A uniform dispersion of biochar and penetration of polymeric matrix into pores of biochar could provide high tensile strength. However, in the case of 5BC1000-PVA, the porous structure of the biochar provided some extension of facilities to form such strong cross-linking but could not recover the loss of tensile strength due to high-temperature degradation of the fibrous and functional groups.

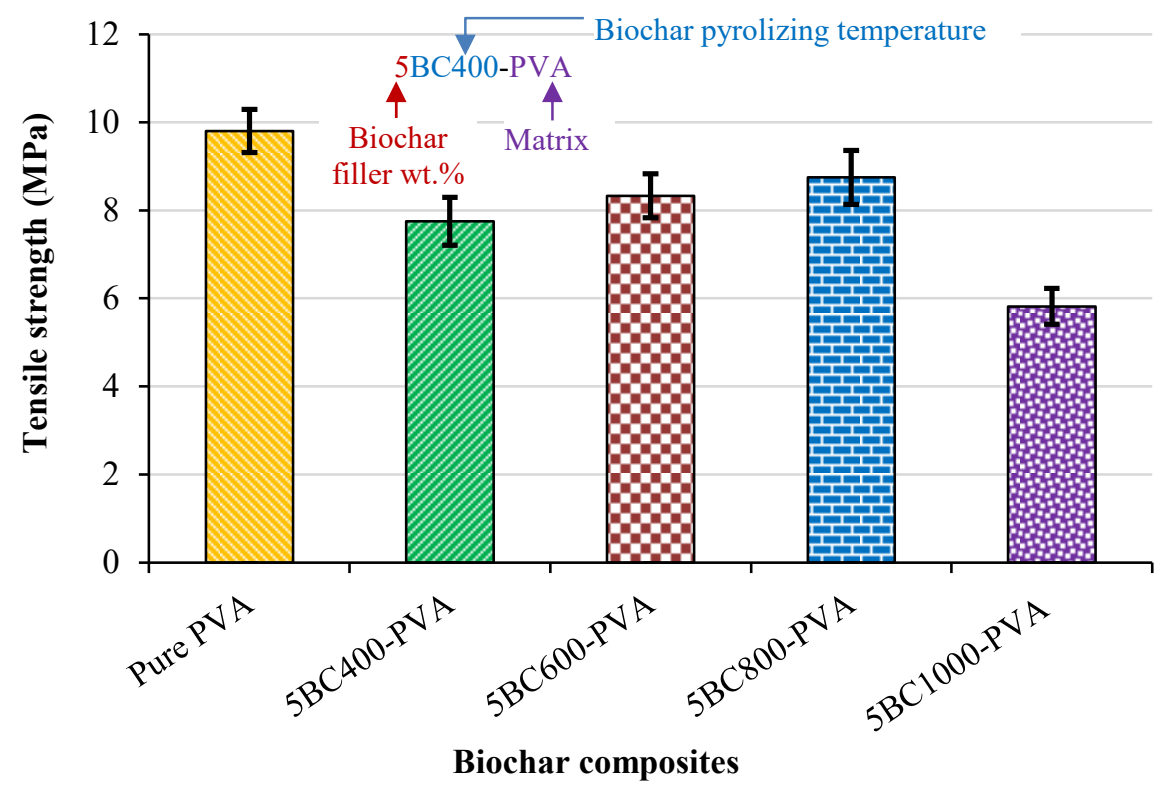

Figure 9. Effect of pyrolyzing temperature on the tensile strength of biocomposite films prepared with 5 wt. $\%$ biochar. 


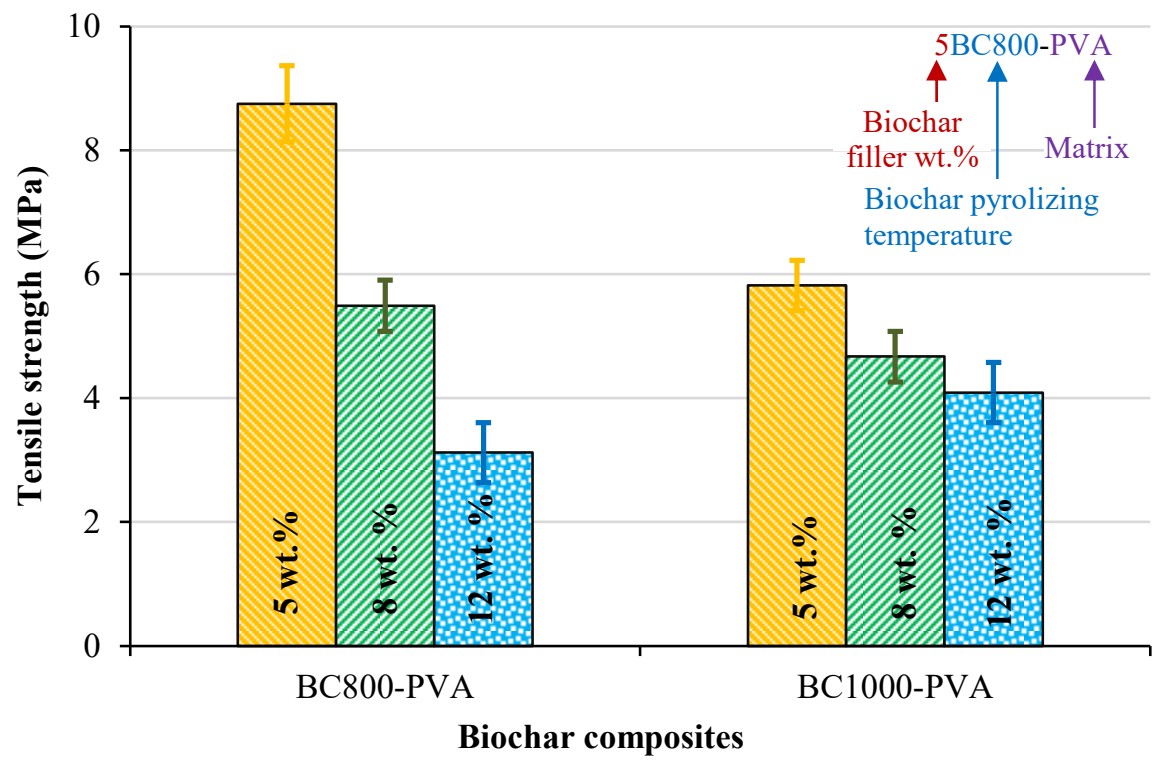

Figure 10. Effect of biochar loading level on the tensile strength of biocomposite films.

As seen in the FTIR data (Figure 6), the reduced peak intensity for the hydroxyl band $(-\mathrm{OH})$ indicated the presence of chemical interaction between the biochar and PVA, which influenced the tensile strength of the biocomposite films. Particle size and distribution were also responsible for this fall of the tensile strength of the biocomposite films [7]. The particle loading level significantly influenced the mechanical strength of the biocomposite films (Figure 10). Increasing biochar content in the BC 800 from $5 \mathrm{wt} . \%$ to $8 \mathrm{wt} . \%$ and finally $12 \mathrm{wt} . \%$ reduced tensile strength from $8.75 \mathrm{MPa}$ to $5.49 \mathrm{MPa}$ and $3.12 \mathrm{MPa}$ respectively. Higher biochar content might introduce flaws within the film, which could negatively affect the tensile strength. A similar trend was also observed for the BC1000. In previous research, the authors reported similar behavior of a composite prepared with brittle biochar and a polymer matrix $[7,8,23]$.

Infiltration of polymer matrix into the biochar pores (in the case of $\mathrm{BC} 800$ and $\mathrm{BC} 1000$ ) may enhance the mechanical strength to some extent. However, in the case of $\mathrm{BC} 1000$, the benefit from the pore structures was suppressed by the disadvantage of non-uniform distribution and irregular shape of the biochar particles [6]. Poulose et al. explained the degradation of tensile strength as the result of poor interfacial bonding between the polymer and the biochar [7]. The particle distribution, dispersion, orientation, and aspect ratio of the reinforcing materials, polymer matrix, and filler adhesion are the vital factors that determine the ultimate properties of the biochar-based composites. Because of the variation in size and shape, orientation, and distribution of biochar particles, the SEM images of biocomposite films with the higher biochar loading levels showed random clusters (particularly for the biocomposite films with BC800 and BC1000) that initiated variation in tensile strength [6].

\section{Conclusions and Future Work}

The key findings of the present research recommended that biochar produced from sugarcane bagasse at higher pyrolyzing temperature could significantly enhance the electrical conductance of the biocomposite films. As evidenced in XRD and FTIR, graphitic carbon having excellent electrical properties was developed in biochar produced during pyrolysis at the higher temperatures $\left(800^{\circ} \mathrm{C}\right.$ and $\left.1000^{\circ} \mathrm{C}\right)$. The minimum content of biochar ( $5 \mathrm{wt} . \%)$ was required to make the composite film electrically conductive. Good interaction between biochar and PVA matrix can improve mechanical properties to a certain extent without recovering the overall loss of strength due to biochar addition. In future, sugarcane bagasse-based biochar and PVA biocomposite film can be improvised by working out 
biochar properties, like chemical and physical surface functionality, purity (ash removing), and controlling particle size. This improvement may facilitate better matrix-filler interaction and result in advanced composite characteristics with better electrical and mechanical properties.

As the main focus of this work was the evaluation of electrical and mechanical properties of biocomposite films, the thermal study of the films is planned as an extension of this work. In the present work, the electrical conductance measurement is carried out at room temperature. In future, the measurement would be carried out at different temperatures to evaluate the effects of temperatures on the electrical conductivity of the composite films. Furthermore, other matrix materials such as polyvinyl chloride (PVC), which is easily soluble in cyclohexanone, can be used for film preparation in the same way as PVA.

Author Contributions: Conceptualization, K.A. and M.H.; methodology, K.A.; validation, K.A., M.H. and J.H.; formal analysis, K.A., M.H. and J.H.; investigation, K.A.; writing-original draft preparation, K.A., M.H. and J.H.; writing-review and editing, K.A., M.H. and J.H.; supervision, M.H. and J.H.; submission, J.H. All authors have read and agreed to the published version of the manuscript.

Funding: This research received no external funding.

Institutional Review Board Statement: Not applicable.

Informed Consent Statement: Not applicable.

Data Availability Statement: The data presented in this study are available within the article.

Acknowledgments: The authors are grateful to the Bangladesh University of Engineering and Technology (BUET), Bangladesh for their technical and financial support during the work.

Conflicts of Interest: The authors declare no conflict of interest.

\section{References}

1. Pawar, P.R.; Rao, P.; Prakash, G.; Lali, A.M. Organic waste streams as feedstock for the production of high volume-low value products. Environ. Sci. Pollut. Res. 2020, 28, 11904-11914. [CrossRef]

2. Guo, X.X.; Liu, H.T.; Zhang, J. The role of biochar in organic waste composting and soil improvement: A review. Waste Manag. 2020, 102, 884-899. [CrossRef] [PubMed]

3. Rushton, L. Health hazards and waste management. Br. Med. Bull. 2003, 68, 183-197. [CrossRef] [PubMed]

4. Xiu, S.; Shahbazi, A.; Li, R. Characterization, modification and application of biochar for energy storage and catalysis: A review. Trends Renew. Energy 2017, 3, 86-101. [CrossRef]

5. Xie, X.; Goodell, B.; Qian, Y.; Peterson, M.; Jellison, J. Significance of the heating rate on the physical properties of carbonized maple wood. Holzforschung 2008, 62, 591-596. [CrossRef]

6. Nan, N.; DeVallance, D.B.; Xie, X.; Wang, J. The effect of bio-carbon addition on the electrical, mechanical, and thermal properties of polyvinyl alcohol/biochar composites. J. Compos. Mater. 2015, 50, 1161-1168. [CrossRef]

7. Poulose, A.M.; Elnour, A.Y.; Anis, A.; Shaikh, H.; Al-Zahrani, S.; George, J.; Tsang, D.C. Date palm biochar-polymer composites: An investigation of electrical, mechanical, thermal and rheological characteristics. Sci. Total Environ. 2018, 619, 311-318. [CrossRef]

8. Wang, M.; Duan, X.; Xu, Y.; Duan, X. Functional three-dimensional graphene/polymer composites. ACS Nano 2016, 10, 7231-7247. [CrossRef]

9. Richard, S.; Rajadurai, J.S.; Manikandan, V. Influence of particle size and particle loading on mechanical and dielectric properties of biochar particulate-reinforced polymer nanocomposites. Int. J. Polym. Anal. Charact. 2016, 21, 462-477. [CrossRef]

10. Das, O.; Bhattacharyya, D.; Hui, D.; Lau, K.T. Mechanical and flammability characterizations of biochar/polypropylene biocomposites. Compos. Part B Eng. 2016, 106, 120-128. [CrossRef]

11. Das, O.; Sarmah, A.K.; Bhattacharyya, D. Biocomposites from waste-derived biochars: Mechanical, thermal, chemical, and morphological properties. Waste Manag. 2016, 49, 560-570. [CrossRef] [PubMed]

12. Das, O.; Sarmah, A.K.; Bhattacharyya, D. Nanoindentation assisted analysis of biochar added biocomposites. Compos. Part B Eng. 2016, 91, 219-227. [CrossRef]

13. Giorcelli, M.; Bartoli, M.; Sanginario, A.; Padovano, E.; Rosso, C.; Rovere, M.; Tagliaferro, A. High-Temperature Annealed Biochar as a Conductive Filler for the Production of Piezoresistive Materials for Energy Conversion Application. ACS Appl. Electron. Mater. 2021, 3, 838-844. [CrossRef]

14. Poulose, A.M.; Anis, A.; Shaikh, H.; George, J.; Al-Zahrani, S.M. Effect of plasticizer on the electrical, thermal, and morphological properties of carbon black filled poly (propylene). Polym. Comp. 2017, 38, 2472-2479. [CrossRef]

15. Das, O.; Sarmah, A.K.; Bhattacharyya, D. A sustainable and resilient approach through biochar addition in wood polymer composites. Sci. Total Environ. 2015, 512, 326-336. [CrossRef] [PubMed] 
16. Khui, P.L.N.; Rahman, R.; Ahmed, A.S.; Kuok, K.K.; Bin Bakri, M.K.; Tazeddinova, D.; Kazhmukanbetkyzy, Z.A.; Torebek, B. Morphological and Thermal Properties of Composites Prepared with Poly (lactic acid), Poly (ethylene-alt-maleic anhydride), and Biochar from Microwave-pyrolyzed Jatropha Seeds. BioResources 2021, 16, 3171-3185. [CrossRef]

17. Sobhan, A.; Muthukumarappan, K.; Wei, L. Development of bio-nanocomposite films by combination of PLA and biochar for smart food packaging. In ASABE Annual International Virtual Meeting; American Society of Agricultural and Biological Engineers: St. Joseph, MI, USA, 2020; p. 1.

18. Sobhan, A.; Muthukumarappan, K.; Wei, L.; Qiao, Q.; Rahman, M.T.; Ghimire, N. Development and characterization of a novel activated biochar-based polymer composite for biosensors. Int. J. Polym. Anal. Charact. 2021, 26, 544-560. [CrossRef]

19. Minugu, O.P.; Gujjala, R.; Shakuntala, O.; Manoj, P.; Chowdary, M.S. Effect of biomass derived biochar materials on mechanical properties of biochar epoxy composites. Proc. Inst. Mech. Eng. Part C J. Mech. Eng. Sci. 2021. [CrossRef]

20. Zhao, H.; Li, X.; Zhang, L.; Hu, Z.; Zhong, L.; Xue, J. Preparation and bacteriostatic research of porous polyvinyl alcohol/biochar/nanosilver polymer gel for drinking water treatment. Sci. Rep. 2021, 11, 12205. [CrossRef]

21. Huber, T.; Misra, M.; Mohanty, A.K. The effect of particle size on the rheological properties of polyamide 6/biochar composites. AIP Conf. Proc. 2015, 1664, 150004.

22. Peterson, S.C.; Kim, S. Reducing biochar particle size with nanosilica and its effect on rubber composite reinforcement. J. Polym. Environ. 2020, 28, 317-322. [CrossRef]

23. Ahmetli, G.; Kocaman, S.; Ozaytekin, I.; Bozkurt, P. Epoxy composites based on inexpensive char filler obtained from plastic waste and natural resources. Polym. Compos. 2013, 34, 500-509. [CrossRef]

24. Myllytie, P.; Misra, M.; Mohanty, A.K. Carbonized lignin as sustainable filler in biobased poly(trimethylene terephthalate) polymer for injection molding applications. ACS Sustain. Chem. Eng. 2016, 4, 102-110. [CrossRef]

25. Nagarajan, V.; Mohanty, A.K.; Misra, M. Biocomposites with size-fractionated biocarbon: Influence of the microstructure on macroscopic properties. ACS Omega 2016, 1, 636-647. [CrossRef] [PubMed]

26. Gaidukovs, S.; Kampars, V.; Bitenieks, J.; Bochkov, I.; Gaidukova, G.; Cabulis, U. Thermo-mechanical properties of polyurethane modified with graphite oxide and carbon nanotube particles. Integr. Ferroelectr. 2016, 173, 1-11. [CrossRef]

27. Gaidukovs, S.; Zukulis, E.; Bochkov, I.; Vaivodiss, R.; Gaidukova, G. Enhanced mechanical, conductivity, and dielectric characteristics of ethylene vinyl acetate copolymer composite filled with carbon nanotubes. J. Thermoplast. Compos. Mater. 2018, 31, 1161-1180. [CrossRef]

28. Bertasius, P.; Macutkevic, J.; Banys, J.; Gaidukovs, S.; Barkane, A.; Vaivodiss, R. Synergy effects in dielectric and thermal properties of layered ethylene vinyl acetate composites with carbon and Fe3O4 nanoparticles. J. Appl. Polym. Sci. 2020, 137, 48814. [CrossRef]

29. Nie, Y.; Zhao, J.; Zhang, Y.; Zhou, J. Risk Evaluation of “Not-In-My-Back-Yard" Conflict Potential in Facilities Group: A Case Study of Chemical Park in Xuwei New District, China. Sustainability 2020, 12, 2723. [CrossRef]

30. Tan, B.K.; Ching, Y.C.; Poh, S.C.; Abdullah, L.C.; Gan, S.N. A review of natural fiber reinforced poly (vinyl alcohol) based composites: Application and opportunity. Polymers 2015, 7, 2205-2222. [CrossRef]

31. Reza, S.M.S.; Islam, S. Utilization Potential of Waste from Sugarcane Factory of Bangladesh as Partial Replacement of Cement in Concrete. J. Environ. Treat. Tech. 2019, 7, 109-112.

32. Zhang, Z.; Zhu, Z.; Shen, B.; Liu, L. Insights into biochar and hydrochar production and applications: A review. Energy 2019, 171, 581-598. [CrossRef]

33. Zhang, X.; Zhang, P.; Yuan, X.; Li, Y.; Han, L. Effect of pyrolysis temperature and correlation analysis on the yield and physicochemical properties of crop residue biochar. Bioresour. Technol. 2020, 296, 122318. [CrossRef] [PubMed]

34. Vieira, F.R.; Romero Luna, C.M.; Arce, G.L.A.F.; Ávila, I. Optimization of slow pyrolysis process parameters using a fixed bed reactor for biochar yield from rice husk. Biomass Bioenergy 2020, 132, 105412. [CrossRef]

35. Gabhi, R.S.; Kirk, D.W.; Jia, C.Q. Preliminary investigation of electrical conductivity of monolithic biochar. Carbon 2017, 116, 435-442. [CrossRef]

36. Sun, Y.; Gao, B.; Yao, Y.; Fang, J.; Zhang, M.; Zhou, Y.; Yang, L. Effects of feedstock type, production method, and pyrolysis temperature on biochar and hydrochar properties. Chem. Eng. J. 2014, 240, 574-578. [CrossRef]

37. Das, O.; Kim, N.K.; Hedenqvist, M.S.; Lin, R.J.; Sarmah, A.K.; Bhattacharyya, D. An attempt to find a suitable biomass for biochar-based polypropylene biocomposites. Environ. Manag. 2018, 62, 403-413. [CrossRef] [PubMed]

38. Terzioğlu, P.; Parın, F.N. Biochar Reinforced Polyvinyl Alcohol/Corn Starch Biocomposites. Süleyman Demirel Üniv. Fen Bilim. Enst. Derg. 2020, 24, 35-42. [CrossRef]

39. Ganguly, S.; Mondal, S.; Das, P.; Bhawal, P.; Das, T.K.; Ghosh, S.; Remanan, S.; Das, N.C. An insight into the physico-mechanical signatures of silylated graphene oxide in poly (ethylene methyl acrylate) copolymeric thermoplastic matrix. Macromol. Res. 2019, 27, 268-281. [CrossRef]

40. Mercader, C.; Denis-Lutard, V.; Jestin, S.; Maugey, M.; Derré, A.; Zakri, C.; Poulin, P. Scalable process for the spinning of PVA-carbon nanotube composite fibers. J. Appl. Polym. Sci. 2012, 125, E191-E196. [CrossRef]

41. Ganguly, S.; Ghosh, S.; Das, P.; Das, T.K.; Ghosh, S.K.; Das, N.C. Poly (N-vinylpyrrolidone)-stabilized colloidal graphenereinforced poly (ethylene-co-methyl acrylate) to mitigate electromagnetic radiation pollution. Polym. Bull. 2020, 77, 2923-2943. [CrossRef]

42. Ogunsona, E.O.; Misra, M.; Mohanty, A.K. Sustainable biocomposites from biobased polyamide 6, 10, and biocarbon from pyrolyzed miscanthus fibers. J. Appl. Polym. Sci. 2017, 134, 44221. [CrossRef] 